Original research article

\title{
Exploring the Enabling Environments, Inherent Characteristics and Intrinsic Motivations Fostering Global Electricity Decarbonization
}

\author{
Diego Ponce de Leon Barido*, Nkiruka Avila, Daniel M. Kammen \\ University of California Berkeley, USA
}

\section{A R T I C L E I N F O}

\section{Keywords:}

Energy transitions

Sustainability

Development

Decarbonization

Data

\begin{abstract}
A B S T R A C T
The need for transitioning towards low-carbon energy systems, and the recent boom in available data, allows for a constant re-evaluation of global electricity sector decarbonization progress, and its underlying theoretical assumptions. Arguably, the existing decarbonization literature and institutional support frameworks focus on top-down supply side mechanisms, where policies, goals, access to financing, and technology innovation are suggested as the main drivers. Here, we synthesize eleven global datasets that range from electricity decarbonization progress, to quality of governance, to international fossil fuel subsidies, and environmental policies, amongst several others, and use methods from data mining to explore the factors that may be fostering or hindering decarbonization progress. This exercise allows us to present numerous hypotheses worth exploring in future research. Some of these hypotheses suggest that policies might be ineffective when misaligned with country specific motivators and inherent characteristics, that even in the absence of policy there are particular inherent characteristics that foster decarbonization progress (e.g., relatively high local energy prices, foreign energy import dependency and the absence of a large extractive resource base), and that the interaction of country-specific enabling environments, inherent characteristics, and motivations is what determines decarbonization progress, rather than stand-alone support mechanisms. We present the hypothesis that existing support mechanisms for decarbonization may be relying too much on blanket strategies (e.g., policies, targets), and that there is a need for support mechanisms that encompass a wider diversity of country-specific underlying conditions.
\end{abstract}

\section{Introduction}

As nations look to decarbonize their electricity sector fuel mix, there is a broad consensus that policies, technologies and long-term goalsetting are the preferred mechanisms for enabling low-carbon transitions [1-4]. Furthermore, these mechanisms have been motivated by climate change mitigation, leaving out a wide range of alternative reasons why countries would choose to pursue electricity sector decarbonization. Countries that are global leaders in low-carbon transitions now appear across a wide range of incomes, regions, and levels of development, suggesting that there are multiple motivations, inherent characteristics, and enabling environments that motivate countries to pursue low-carbon pathways [5-7].

Costa Rica, Nicaragua, and Kenya, are three unconventional examples of countries that have taken significant steps towards the goal of $80 \%$ electricity decarbonization by 2050 , and are over-performers relative to other countries in their income group (Fig. 1). These three countries demonstrate disparate motivations for electricity sector decarbonization and yet have some of highest proportions of electricity generation from non-hydropower renewable energy (24\%, $46 \%$, and $46 \%$ respectively) amongst low and low-middle income countries ( $\$ 13,600, \$ 4500$, and $\$ 2800$ per capita respectively). Comparatively, other global low-carbon transition leaders such as Denmark, Germany, and Portugal had a negligible fraction of electricity generation from non-hydropower renewable resources when they were at a similar stage of economic development ( $\sim 7000$ GDP per capita). This trend highlights that renewable energy technologies have become, on average, increasingly cost-competitive for many countries across the entire income spectrum, and illustrates the diversity and importance of other mechanisms besides climate change mitigation policies to motivate decarbonization (Fig. 1).

The existing literature is encompassing of a variety of theories of the key drivers of electricity decarbonization, yet, it is still divided about the determining mechanisms, drivers, and kindling factors that foster decarbonization progress [8-10]. Arguably, and despite the variety of existing theories, international support frameworks have followed a

\footnotetext{
* Correspondence to: CITRIS Foundry - 4th Floor, 330 Sutardja Dai Hall, MC 1764, Berkeley, CA 94720-1764, USA.

E-mail address: diego.leon@berkeley.edu (D.P.d.L. Barido).
} 


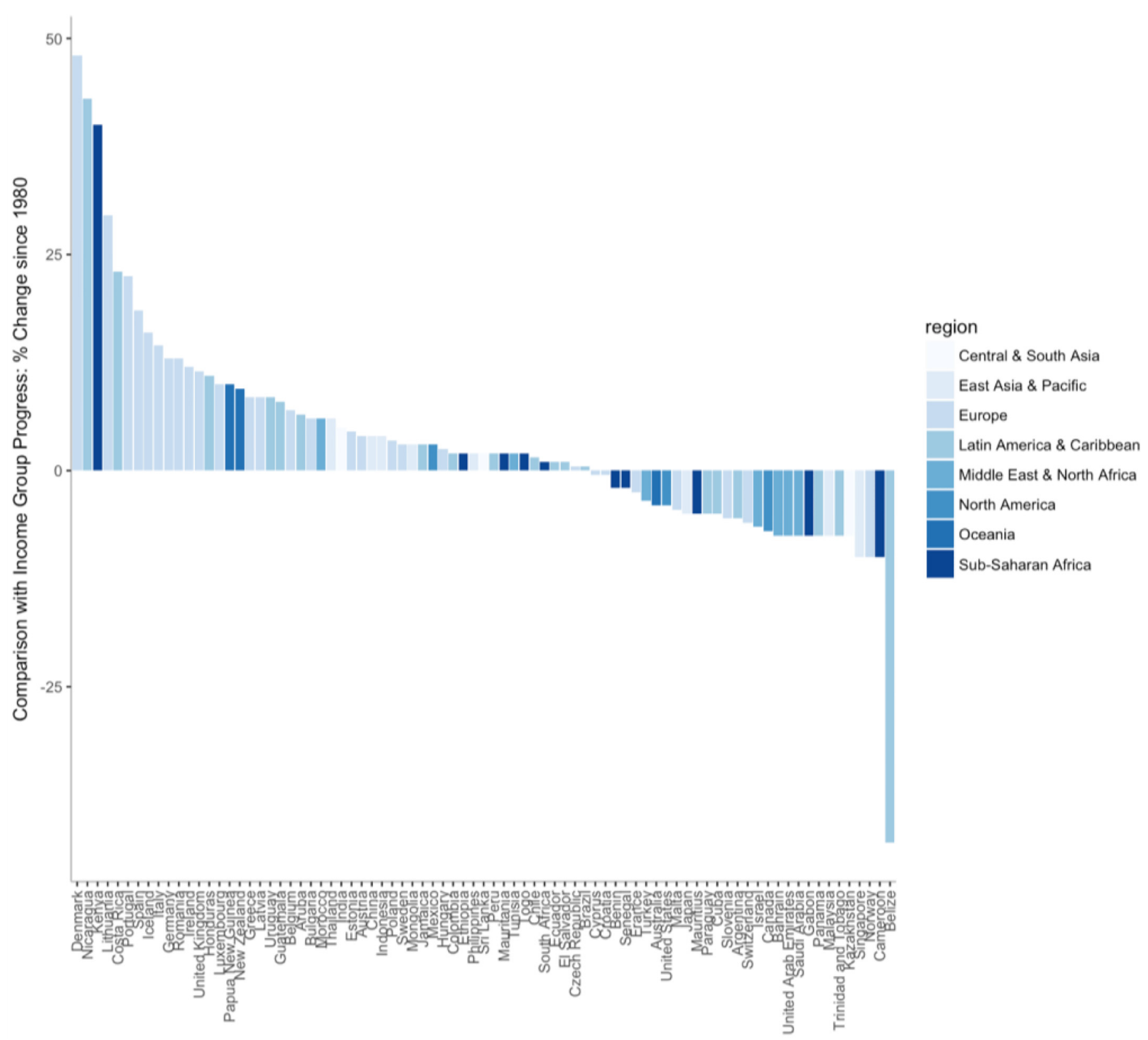

Fig. 1. Over and underperformers in electricity system decarbonization progress: The y-axis depicts the difference between a country's electricity sector decarbonization progress and the progress of the cluster income group to which it belongs. Electricity sector 'decarbonization progress' is defined as the difference between total percentage electricity generation from non-hydropower renewable resources between 1980 and 2014, or latest data available. Countries were clustered by income (low-income $\leq \$ 10,000 \mathrm{GDP} /$ Capita, $\$$ US $10,000<$ low-middle income $\leq \$ 20,000$, $\$$ US $20,000<$ high-middle income $\leq \$$ US 45,000 , and $\$$ US $45,000<$ high-income). The median income value of each income cluster was calculated, and a relative progress score is assigned to each country by subtracting its decarbonization progress since 1980 from the median progress score of the income cluster to which it belongs.

blanket strategy of policies and targets, ignoring that these support mechanisms might be deemed ineffective - or significantly slowed down - in a variety of country-specific contexts.

Some schools of thought argue that the combination of demand-pull and technology-push policy instruments are essential for transitioning towards low-carbon energy systems [11]. Others, argue that the coevolution of energy flows and markets, available technologies, and policy regimes determine decarbonization progress [12-17]. Alternatively, others propose multi-level perspectives, suggesting that the intersection of socio-technical systems (e.g., infrastructures and energy markets), niche innovations (e.g., disruptive technologies and business models), and exogenous slow-changing developments (e.g., demographics and ideologies) determines decarbonization progress [18-20].
Non-policy related decarbonization drivers such as industry lobbying (e.g., manufacturing), quality of governance, political ideology, political support and leadership type have been suggested to also play a critical role in the pace of decarbonization [21,22].

Some literature also emphasize geographical perspectives on transitions, and put forth the notions of context, space and place of nations as the necessary foreground to the impact that changes in socio-technical systems have on decarbonization [23]. Accordingly, there are also arguments that civil society and social movements are at the core of long-term support and progress towards decarbonization [24-26].

When discussing the adoption of particular renewable energy resources, the literature suggests that the role and importance of first adopters varies across technologies, with the evidence suggesting that 


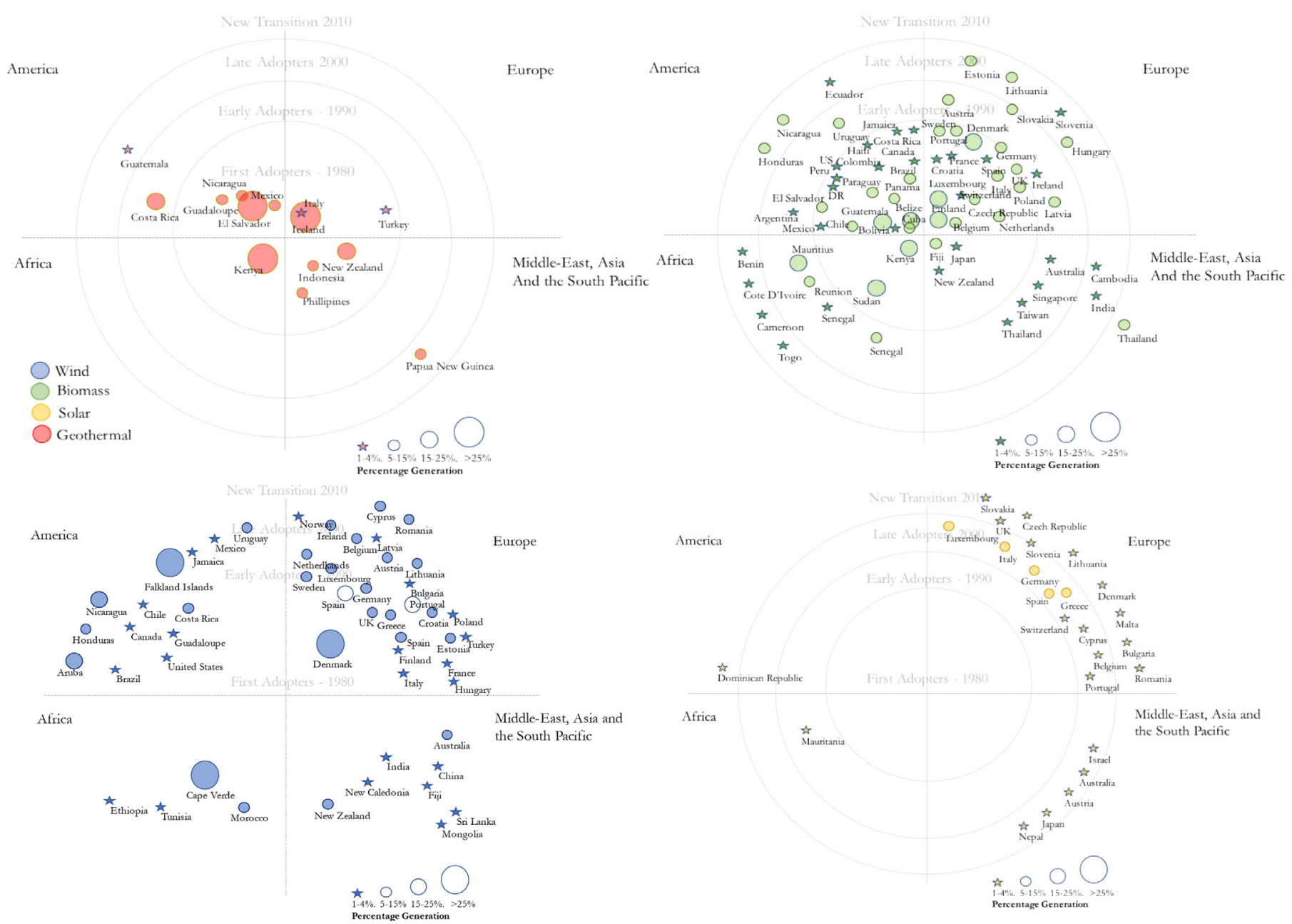

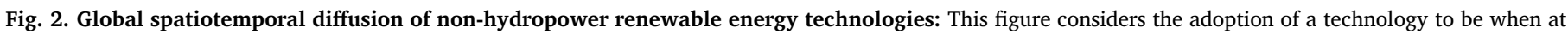

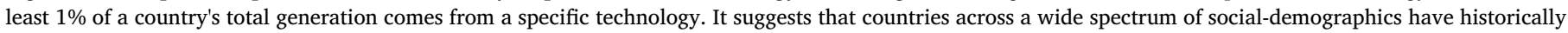

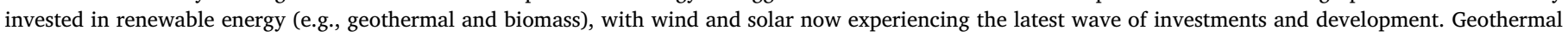
energy has seen very little growth in recent decades, despite its large potential.

they are more important for the global diffusion of wind and solar, than for geothermal and biomass [27-29]. Fig. 2 depicts the spatio-temporal diffusion of these technologies. Biomass for electricity generation has seen widespread adoption for many decades, with Europe and the Americas both being first adopters, albeit with different sustainability practices. While most early adopters and countries in Europe have slowly increased or diversified their sources of biomass production together with the adoption of best practices (trees, arable crops, algae and other plans, agricultural and forest residues, effluents, sewage sludge, manures, industrial by-products, organic municipal waste, and imported biomass) [30-33], first adopters in the Americas and Africa have seen a more unstable path with half of the first adopters experiencing a significant decline in production due to a variety of factors including the cost-competitiveness of other fuels and technologies, supply-chain efficiency, unsustainable practices, climate change impacts, and in some cases violent conflict [34-39]. Geothermal developments have also seen early global adoption with the notable cases of Iceland, Kenya and El Salvador. While Central American countries (El Salvador, Nicaragua, Costa Rica, and Guatemala) have continued to increase the adoption of geothermal energy in their energy mix, countries in the Rift Valley, which have a large geothermal potential [40], have not followed Kenya's path despite Kenya doubling its production in 2014 (40\%). All first adopters, except for the Philippines, El Salvador, and Mexico, whose production declined but are still pursuing the resource, have continued to invest in further development. Still, despite the presence of these first adopters, the observed benefits to energy security as a cost-effective baseload, and nascent solutions to mitigate the uncertainties and financial risks associated with drilling geothermal wells on green fields, the global geothermal resource remains largely undeveloped $[41,42]$. The diffusion of wind and solar technologies have been explored extensively by the literature, with a diversity of factors being suggested as the preconditions for technological adoption including policies to support the growth of the power sector, local environmental, social, economic and political variables, support for innovation, industrial development, and technological change, learning and R\&D support (and consequent reductions in investment costs), feed-in-tariffs, financial incentives and production-tax credit schemes, household social-demographics, resource potential, and spatial variability, local electricity cost, and the emergence of China and India as global players in solar and technology development, among others [24,43-46,28,47].

Finally, an emerging area of the literature is beginning to explore the differences in the decision-making logic around renewable energy technology adoption in the rising south. An interesting concept is that of the 'electricity ladder' in which, as per capita income increases, countries transition from domestic resources, to imported fuels, and finally to capital-intensive modern electricity sources; with domestic energy endowments hindering upwards progress on the energy ladder [48]. In addition, new data and research suggest that low, middle-income countries are able to move up on this energy ladder (at times, 
leapfrogging it) by accessing the global experience of earlier adopters (high-income countries) in order to accelerate domestic market growth. Late adopter countries have experienced accelerated growth rates for wind and solar energy which are 4.7 and 16 times faster than early adopters, respectively [49]. In this process, some research suggests that subsidies have helped foster renewable energy growth in low-income countries, while feed-in tariffs have fostered renewable energy growth in middle-income countries [50]. These results suggest a renewable energy policy ladder of sorts, with policy and enabling environments (e.g., electricity market conditions, political capture, and the interaction of administrative capacity with the complexity of renewable energy policies) affecting low, and middle-income groups differently [50].

Together, this research suggests, that innovation and policy formulation is not sufficient in countries with an "institutional gap", and suggests that deep knowledge of local contexts, clear and strong financial incentives, predictability of government decision making, and streamlined permitting procedures are as important (or more) as the existence of innovation and policy formulation [51,52]. Like the energy transitions literature suggests, the repertoire of policies for late technology adopters should be very different from those established by first adopters and early pioneers, especially if the technology carries low risk [27]. The recognition of this central issue is key to designing incentives that work specifically for countries who want to simply adopt technology, and do not seek to invest in research and development of a new industry like market leaders tend to prefer. This is the case of many countries in the global south. As policies like renewable energy goals, renewable portfolio standards, and feed-in tariffs have begun to implemented globally, it is becoming increasingly more important to consider that a country's context (e.g., local prices, geography, social, political) might be equally important, or more, to making progress or hindering electricity sector decarbonization progress than policies alone [53,54].

As shown in Table 1 with regards to the methodology that is used to study electricity sector transitions, we find that there is a preference for political economy, multiple case study comparative analysis and traditional methods of statistical hypothesis testing, and econometrics, rather than data mining (Table 1). Overall, these papers suggest that policy instruments are effective but insufficient drivers of decarbonization, and that countries that employ multi-dimensional decarbonization mechanisms that are based on economic, environmental and social factors have a more successful deployment rate of renewable energy. Many of the studies that use econometrics and/or traditional methods of statistical hypothesis testing use only one data source, rather than pooled data from different sources to perform their analysis. Furthermore, many of the studies in the literature may experience sample selection and omitted variable bias. The first leads to selecting a non-random or incomplete sample, that can lead to either an overestimation or an underestimation of research results. The latter, may lead to attributing the effect of a missing variable to the included variables in the model, potentially overestimating the research results.

While some of the methods used in traditional statistical hypothesis testing and data mining might be the same, the intention and the way in which the analyses are performed are very different. Data mining is used, in general, to explore and discover patterns and knowledge from data. It is commonly used as a data exploration step, rather than for hypothesis testing [55]. A big difference between data mining and econometric analysis, for example, is that the latter establishes hypotheses before data exploration and analysis begins. Econometric models and traditional methods in traditional statistical hypothesis testing establish a theoretical framework upon which data is collected and a model is built. Data mining approaches collect as much data as possible, and then implements techniques to identify patterns, groupings, clusters and prediction, without a prior theoretical framework. We expound on these differences in the methodology section.

Data-driven approaches and thought frameworks derived from behavioral science are also missing from the literature discourse regarding top-down climate change decision making and global decarbonization progress [56,57]. This paper aims to fill this gap by integrating a mixture of data mining methods, behavioral science theory, and historical perspectives to uncover key features of the global low-carbon electricity sector transition. Rather than choosing a few countries to perform our analysis, we gather data from 130 countries and 10 global datasets of energy, electricity, economic, sustainability and social progress (among others) and employ a variety of data mining methods to extract key features that may be driving decarbonization across regions, incomes and levels of development. We shed light on features of electricity sector level transitions that are once again emerging, some that are changing, and new themes that require attention.

We define inherent characteristics as those that are both very difficult and/or that would take a long time to change in a country. For example, population and land size can change over time, but the first requires either a very long time to observe a large change or an abrupt shock (e.g., war), while the latter requires redrawing of a country's borders either through diplomacy or war (among other methods). Other, perhaps less discernable inherent characteristics include a select group of economic indicators which, on average, can take many decades to observe any discernable change. Here we include income per capita, inequality, level of corruption, quality of governance and infrastructure, level of foreign investment dependency, and levels of dependency on resource rents. These characteristics are very different from enabling environments, or characteristics that can change from one year to the next. We suggest enabling environments as those characteristics which, in theory, could significantly affect inherent characteristics over long periods of time. Enabling environments include the number or renewable energy policies, the amount of investments in renewable energy per area and per capita, and energy prices. Politicians and international financial institutions can, in a matter of months or years, pass new policies, agree on investment amounts and begin spending, and or increase or reduce energy prices pursuing political or policy related objectives. Inherent characteristics and enabling environments play different roles in electricity decarbonization and we expound on this further below. Motivations have a much clearer distinction than enabling environments and intrinsic characteristics. In our data, we observe countries that pursue electricity decarbonization for a diverse set of reasons. Some seek simply to minimize the cost of their optimal power dispatch, while others seek to increase electricity access and grid expansion at least cost. Others pursue electricity decarbonization in parallel to energy independence efforts, while others pursue it with motivations related to climate related goals and costminimization objectives.

Our work highlights three research gaps in the literature: a gap in support mechanism strategies, a methodological and data gap, and a lexicon gap. First, our literature review and data exploration suggest that there are no blanket support mechanism strategies for electricity sector decarbonization progress, or 'one size fits all' policy approaches. Rather, it suggests that the complex interaction between enabling environments, inherent characteristics, and motivations contribute to either fostering or hindering decarbonization progress. Second, we contribute methodologically by using 10 data sets over several decades to explore decarbonization-related data using exploratory data analysis and data mining methods to elucidate new groupings, clusters, new research questions and hypotheses that are worth exploring. This approach can help research that relies on confirmatory data analysis to avoid statistical issues related to double-dipping, sample selection bias, and omitted variable bias that are common in the literature. Finally, while the literature suggests that the factors determining decarbonization progress fall into 'two buckets' (policy and non-policy drivers), we argue that this vision is limited, and we propose the hypothesis that we should cluster countries across inherent characteristics, enabling environments, and motivations.

The next section describes the global electricity, energy, economic, sustainability and development data used in this analysis, and the 


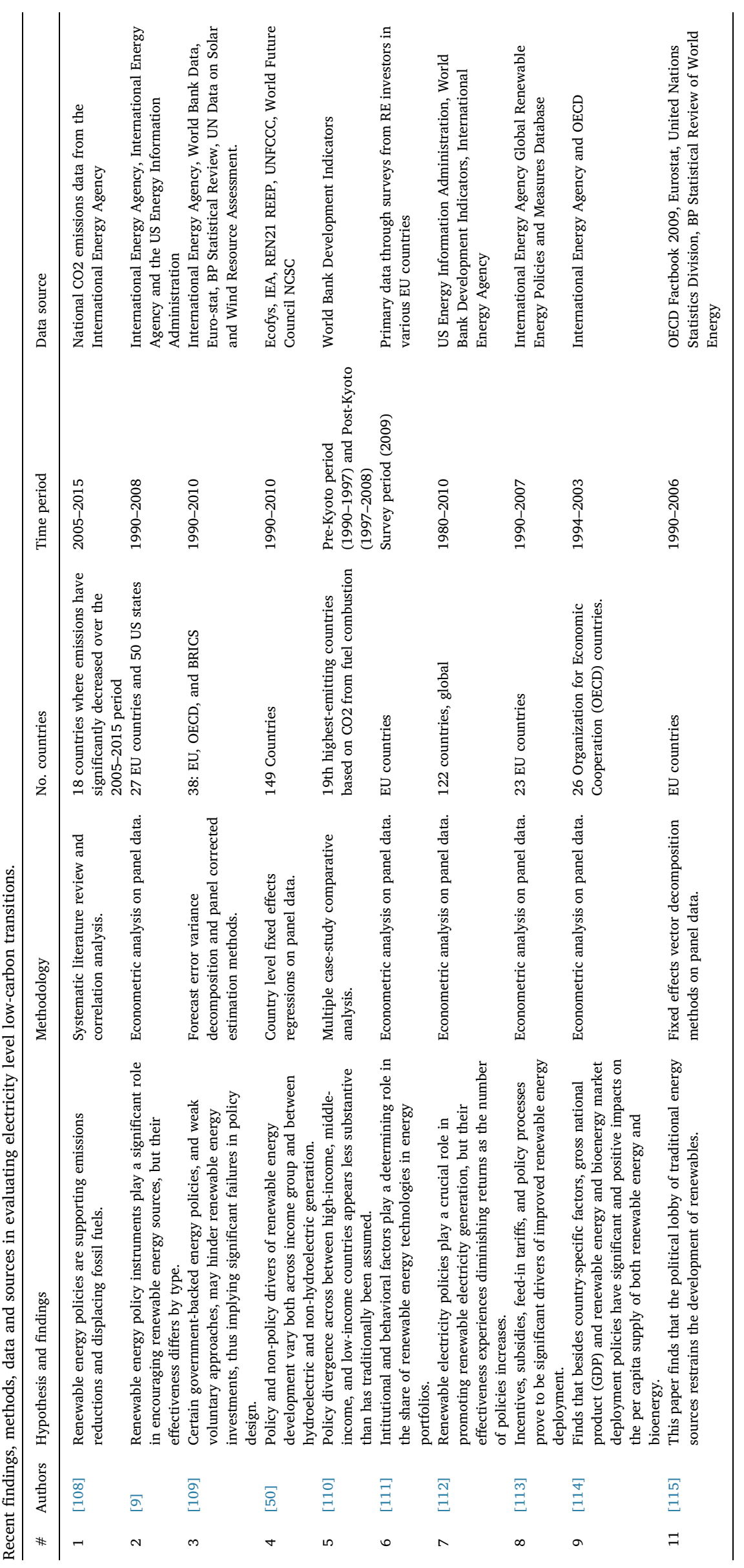


statistical and data mining approach employed. The results and discussion section incorporate insights from behavioral science literature to propose new hypotheses worth exploring at the intersection of enabling environments, motivations, and inherent characteristics. The last section concludes.

\section{Materials and methods}

\subsection{Global energy, sustainability and development data}

We collect and synthesize data for 190 countries and territories from the World Bank Development Indicators [58], Bloomberg New Energy Finance's Climatescope [5], the Energy Information Administration [59], the Quality of Governance Initiative [60], the International Energy Agency and IRENA's joint policies and measures database for global renewable energy [61], the International Monetary Fund's fossil fuel subsidies database [62], the Global Footprint Network [63], the United Nations Human Development Indicators [64], Yale's Environmental Performance Index [65], the Social Progress Imperative data [66], and the World Energy Council [67].

These data include a variety of measures and proxies for sustainability, foreign energy import dependence, local resource dependence, governance and quality of institutions, renewable and climate related policies, human development, energy financing, resource consumption (e.g., electricity demand, total energy demand growth rates, electricity and total energy demand rates of change), and country specific characteristics such as land size, population, population density, and gross domestic product, among many other variables. We clean and merge the data to create a 130-country dataset that contains the majority of the aggregated features. We then plot and analyze correlations across variables, and perform our analysis on a subset of 76 countries where generation from non-hydropower renewable resources has increased by more than 1\% between 1980 and 2014 (or year of latest data). We further subset these data from 76 countries into two groups that are above or below an average income per capita \$US 30,000 (31 and 45 countries respectively). More details on the data and the data cleaning process are available in the Supplementary Information. All data and code are available by contacting the authors.

\subsubsection{Methodology}

Our analysis is an illustration of techniques that can be employed for exploring data, and elucidating new hypotheses and questions, rather than pursuing causal inference. In general, data mining is used to explore and discover patterns and knowledge from data [55]. Some of the results of a data mining exercise include visualization, the identification of multiple groups in data (clustering), anomaly detection, exploration of relationships and dependencies across variables, classification, and summarization, among others. We use all these techniques in our analysis. It is commonly used as a data exploration step, rather than hypothesis testing, and often uses the same methods as traditional statistical hypothesis testing. Performing statistical hypothesis testing after extensively exploring data, however, is called 'data snooping', and may lead to 'double dipping' or 'circular analysis' - potentially misconstruing the results from hypothesis testing (as opposed to preplanned statistical hypothesis testing, where a researcher establishes hypotheses before data exploration and analysis). In this paper, we take a data mining approach to the data we have gathered in an attempt to discover research gaps, new groupings, and relationships, as well as elucidating new research hypotheses that are worthwhile pursuing. We employ some of the most common methodologies in a data mining exercise including visualization, principal component analysis, principal component regressions, clustering, and prediction. Our goal is not to test hypotheses, but rather, to explore new data and bring to light new questions.

We use principal component regressions (PCR) to reconstruct a dependent variable that tracks electricity sector 'decarbonization progress' defined as the difference between total percentage electricity generation from non-hydropower renewable resources between 1980 and 2014, or latest data available. PCR is a regression technique based on principal component analysis (PCA), where it uses the principal components as predictors in a linear regression model fitted using least squares $[68,69]$. PCR is valuable as it aids in performing dimensionality reduction, avoidance of multicollinearity between predictors (can be run on highly correlated or even collinear data), it drops components that do not explain much variance in the data, and mitigates overfitting. Principal component analysis extracts features that capture the most variance in global decarbonization datasets, and a k-means algorithm clusters countries across the most important features in global energy, environment and development data. We use y-scaled principal component regressions to reconstruct a dependent variable that measures progress in enabling a low-carbon electricity sector level transition which we define as the difference between total percentage electricity generation from non-hydropower renewable resources from 1980 to 2014, or latest data available [70]. Our proxy for decarbonization progress measures the growth, or decline, in the contribution of nonhydropower renewable energy towards electricity generation across three decades for countries with available data.

We first log-normalize variables with a skewed distribution and perform a feature scaling methodology where all features are scaled with respected to our dependent variable (predictor variables are rescaled to be in $y$-units). After statistical significance pruning and dimensionality reduction on the whole data, we implement a principal components regression methodology to estimate decarbonization progress by using the principal components that capture most of the variation. We choose this method rather than a model-driven hypothesis testing framework, as we are not testing a particular hypothesis, but rather, are attempting to extract the features that may best predict decarbonization progress from these data. On the full data set, we are able to capture $60 \%$ of the variation with the first 20 principal components, and are able to capture $70 \%$ of the variation with 20 principal components in the lower-income subset of countries. Afterwards, a kmeans algorithm using the top 20 principal components for both income groups is used to extract the countries that are part of each cluster. We use the elbow method and silhouette scores to determine the optimal number of country clusters within each of the top 20 principal components.

\section{Results and discussion}

Analyzing the contribution of each variable in our data to every principal component allows us to explore which variables better capture variance in our data, and thus present new hypotheses about global decarbonization progress. We use principal component loadings to understand the relationship and contribution of each variable in our data to each principal component. Principal component loadings depict the correlation between each component and the original variable, and squaring them tells us the amount of variation that each variable contributes to each principal component. In the full dataset, there are several features that emerge as useful predictors of decarbonization progress. We categorize these features into inherent characteristics, enabling environments, and motivations, and key examples are shown in Table 2.

When we perform our analysis on the subset of countries with income per capita below \$US 30,000, we find that local energy prices (fuel and electricity), foreign energy import dependency, investments per capita and per $\mathrm{km}^{2}$, and historical early investments in renewable energy (such as biomass for electricity and geothermal) have more predictive power, whereas the predictive power of variables describing quality of governance infrastructure and policy support for renewable energy is significantly reduced. Further explanation of our methodology and results appears in the supplemental information. 
Table 2

Dimensions of decarbonization.

\begin{tabular}{|c|c|}
\hline Dimension & Key examples \\
\hline Inherent characteristics & Population, land size, income per capita, inequality, quality of governance, level of foreign energy dependency, level of dependency on resource rents. \\
\hline Enabling environments & Renewable energy policies, investments in renewable energy per area and per capita, energy prices. \\
\hline Motivations & Social progress, local sustainability, energy independence, climate change mitigation, political leadership. \\
\hline
\end{tabular}

Our next step was to determine the optimal clusters of clusters for the top 20 principal components in each data set, and extract the countries that were part of each cluster. The full dataset has three stable clusters, and the data subset of countries with income per capita below \$US 30,000 has five stable clusters. For the former, countries are grouped according to land size, energy dependency, energy intensity of the economy, subsidies to fossil fuels and electricity, and rates of economic growth. For the latter, a different set of variables cluster the data including inherent characteristics, and enabling environments. Additional details on the data, figures, statistics and methodology are presented at length in the Supplementary Information.

As described above, the features that best predict decarbonization progress can be clustered into two dimensions: inherent characteristics and enabling environments. Features with predictive power that are positively correlated with progress in decarbonization in both income groups include income per capita, investments in renewable energy per $\mathrm{km}^{2}$ and per capita, levels of foreign energy import dependency, energy prices (e.g., gasoline, retail, industrial, commercial and residential electricity prices) and early historical investments in renewable energy such as biomass and geothermal energy. Features with predictive power that are negatively correlated with progress in decarbonization include increasing levels of dependency on resource extraction, subsidies to fossil fuels, and levels of economic dependency on the export of fossil fuels. Features with predictive power that are only present in the full data (includes countries with an income per capita above and below \$US 30,000) but not the lower income group include the human development index, number of policies passed to foster renewable energy, a variety of metrics for measuring international aid, and the quality of governance and infrastructure. The following sections unpack the data and results within our principal component regressions and analysis, and propose several new hypotheses for improving our understanding decarbonization progress. We frame results from our analysis by focusing on inherent characteristics, enabling environments and motivations. Full descriptions of the results from the principal component regressions are available in the supplemental information.

\subsection{A spectrum of political environments, policies, and quality of governance}

The raw data and analysis employed here suggest that progress in global decarbonization is occurring across a spectrum of political and policy enabling environments, and diverse qualities of governance and infrastructure [59,61]. Fig. 3 depicts a diversity of enabling environments: countries with great carbon responsibility and many policies making little progress (e.g., USA and China), countries passing policies yet moving slowly or even going backwards (e.g., Mexico, Canada, Indonesia, and Paraguay), countries with few policies yet transitioning rapidly (e.g., Iceland, Nicaragua, and Kenya), and clusters of countries where more policies may enable or foster change (e.g., Germany, Spain, Denmark, Lithuania, Ireland, and Costa Rica). Countries with relatively low-scores with regards to quality of infrastructure and governance are performing equally as well, and in some cases, better than countries with conventional notions of good governance and infrastructure.

Even in the absence of major climate change policy instruments, countries in the rising south have been making rapid progress towards decarbonization, catalyzed by various motivations and using a wide range of different approaches. We highlight a few prominent cases:
Nicaragua, Uruguay, Morocco, Honduras, Kenya, Brazil and Chile. Some of these motivations include energy independence and security, as well as the opportunistic economic profit from regional interconnections, for countries such as Nicaragua (46\% non-hydro renewable energy generation) [71], Uruguay (16\%), and Morocco (7\%) $[72,73]$. Others have unique motivations, enabling environments and inherent characteristics such as Honduras (11\%), which recently became the first non-island country in the world to have $10 \%$ solar capacity despite an institutional breakdown and its current violent crime crisis $[74,75]$. Also Costa Rica (24\%), which has a long tradition of conservation and environmental stewardship surrounding coffee and eco-tourism, and Kenya (46\%), whose crippling droughts in the $1990 \mathrm{~s}$ incentivized the country towards a power sector reform and early investments in geothermal [76]. Furthermore, Brazil (10\%), despite large hydropower generation, oil dependency, and current political instability, has one of the most progressive solar net-metering policies in the world (and one of the most progressive uses of biofuels) [77,78], and Chile (10\%), has seen renewable energy progress motivated by the provision of cheap power to the power-hungry mining industry in the northern part of the country [79].

Denmark's global leadership in wind energy development dates back to the 1900s, but it was the energy crisis of the 1970s that motivated its decarbonization, combined with enabling environments such as grassroots opposition to nuclear energy and community-driven wind cooperatives, that have catalyzed the low-carbon transition the country observes today [80,24,81-85].

For the United States, it is meaningful to consider change beyond the nation as a whole, as the national politics of climate change become insurmountable. Cities and states continue to make much faster progress than the nation by creating enabling environments through policy action and opportunistic investments. California, New York and Hawaii have created enabling environments for decarbonization by adopting aggressive renewable energy policy goals ( $50 \%$ by 2030 for California and New York, and $100 \%$ by 2045 for Hawaii) [86-89], while states like Iowa, South Dakota, and Kansas produce the nation's largest shares of wind energy generation (31\%, 26\%, and $24 \%$ respectively) [59] through opportunistic investments. Interestingly, the latter are the nation's wind energy generation leaders while also being more rural and republican-majority states, and having more relaxed policy targets than California, New York and Hawaii, suggesting that there are multiple and equally important motivations for pursuing energy system decarbonization.

\subsection{Inherent characteristics and enabling environments as drivers of global electricity sector decarbonization}

Results from our analysis present the hypothesis that features such as relatively high energy prices (e.g., fuel, commercial, retail and spot prices), renewable energy investments per capita and per $\mathrm{km}^{2}$, and energy import dependency create enabling environments and are associated with a faster pace of decarbonization (Figs. 4 and 5A). Beyond enabling environments for decarbonization, here we highlight how the inherent characteristics of countries create opportunities or barriers for achieving decarbonization.

Features that are negatively correlated with decarbonization progress include a large dependency on natural resource rents as a percentage of GDP, a high percentage of fuel exports as merchandise 


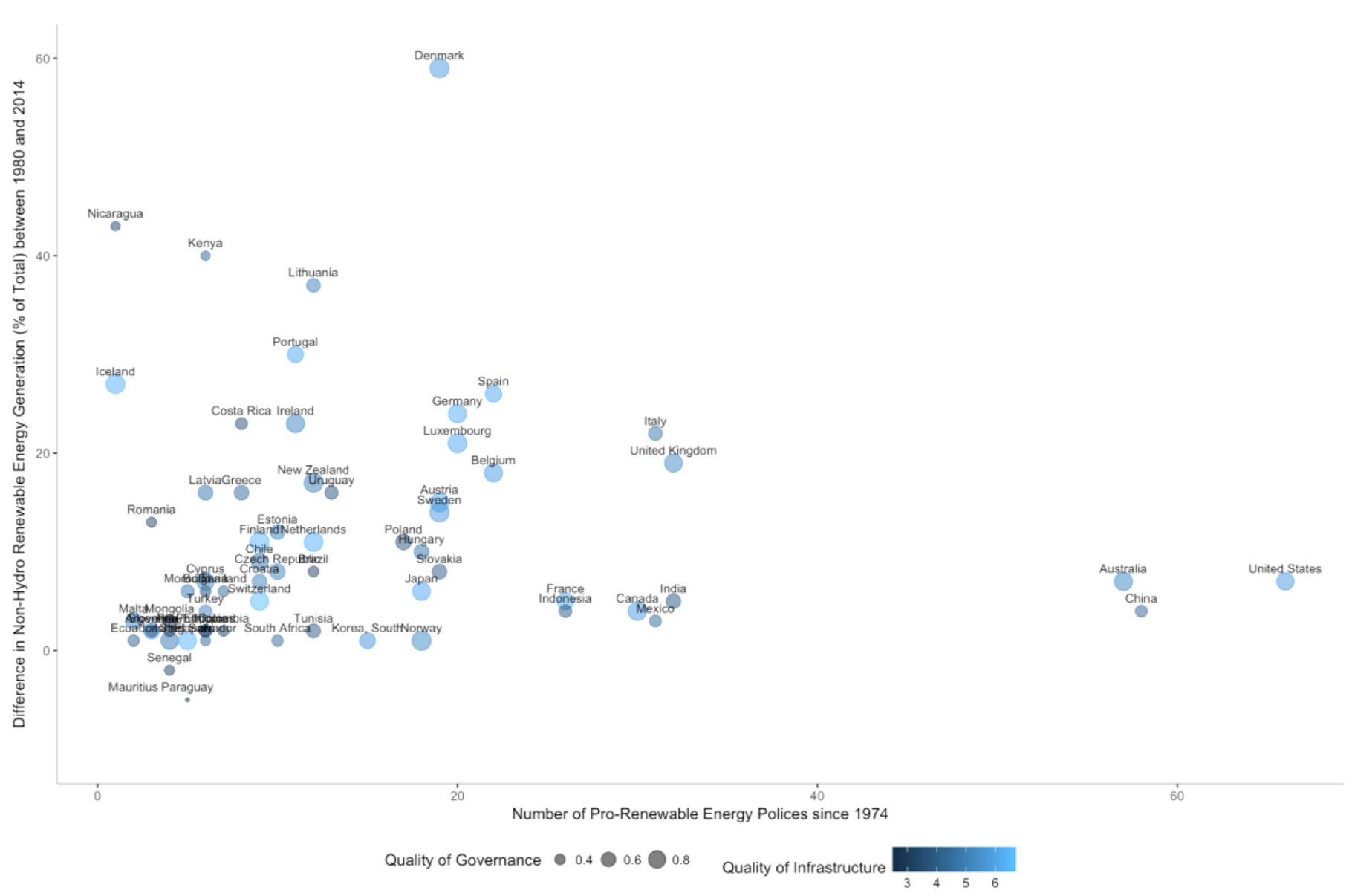

Fig. 3. Quality of governance, infrastructure, number of energy policies since 1974 and decarbonization progress. The figure depicts the difference between total percentage generation from non-hydropower renewable resources between 1980 and 2014 as a function of the number of pro-renewable energy policies passed since 1974, and Quality of Governance and Infrastructure.

exports, and being a large net energy exporter (Fig. 5A and B). Conversely, relatively high energy prices (e.g., fuel, commercial, retail and spot prices), renewable energy investments per capita and per $\mathrm{km}^{2}$, and energy import dependency are associated with a faster pace of decarbonization.

Fossil fuel lock-in and a large dependence on fossil fuel exports should present weariness for global decarbonization policy makers. The United States is set to become a net energy exporter within the next decade [90]; China provides the largest amount of fossil fuel subsidies in the world (while almost single handedly having catalyzed the drop in solar PV prices) [62] and several top-ten $\mathrm{CO}_{2}$ emitters such as Russia, Iran, and Saudi Arabia are all largely dependent on resource rents (Fig. 5B). In addition to the vast existing literature regarding the economic impacts of a large dependency on fossil fuel exports, new literature details how there could be an emerging wave of carbon lock-in affecting the rising south through the global renaissance of coal [91,92]. While this scenario may seem daunting, it is important to highlight that the data also suggests that there exists enabling environments and intrinsic characteristics that present pockets of opportunity where long-term decarbonization could be enabled. Countries without a strong natural-resource-rents dependency and energy import dependent, with relatively high energy prices, with relatively higher renewable energy investments per capita and per $\mathrm{km}^{2}$, could make significant progress towards long-term decarbonization (Fig. 5A and B).

In these observations, only Chile and Papua New Guinea (PNG) appear as outliers with vast fossil fuel and mineral resources, hence are vulnerable to carbon lock-in and fossil fuel export dependency. However, the two are making significant progress towards decarbonization. In Chile, solar and wind investments are displacing fossil fuel expenditures in mining. Chile's mines produce the largest amount of fine copper, the second largest amount of gold, and half the world's lithium, with mining consuming approximately $85 \%$ of capacity in its northern electricity grid [79]. PNG was the first country to submit the final version of its nationally determined contributions at the Conference of the Parties climate negotiations in Paris. PNG's economy is greatly reliant on the export earnings from minerals and energy extraction [93] and thus far has only developed about $2 \%$ of its high potential for renewable energy. Without specific measures such as feedin tariffs, or green certificates, PNG - with large geothermal potential has begun attempting to shift towards the adoption of renewables in an effort to reduce local consumption of fossil fuels and increase the profitability of from the mineral and petroleum sectors [93-95].

\subsection{Motivation as a key driver for electricity sector decarbonization progress}

Taking into account the existing literature, results from our exploratory analysis, and the numerous challenges to increase the pace of global electricity decarbonization (e.g., political, institutional, technological and behavioral) [91] we suggest that it is it is crucial to define new strategies and support mechanisms to rekindle efforts towards global decarbonization. Climate change mitigation is often cited as the main motivation for decarbonization, with contingent monetary rewards, global meeting invitations, and capacity-building exercises made available if countries create enabling environments to achieve those goals. There has been little discussion, however, about the creation of support mechanisms geared towards other motivations besides climate change that can catalyze long-term low-carbon electricity 


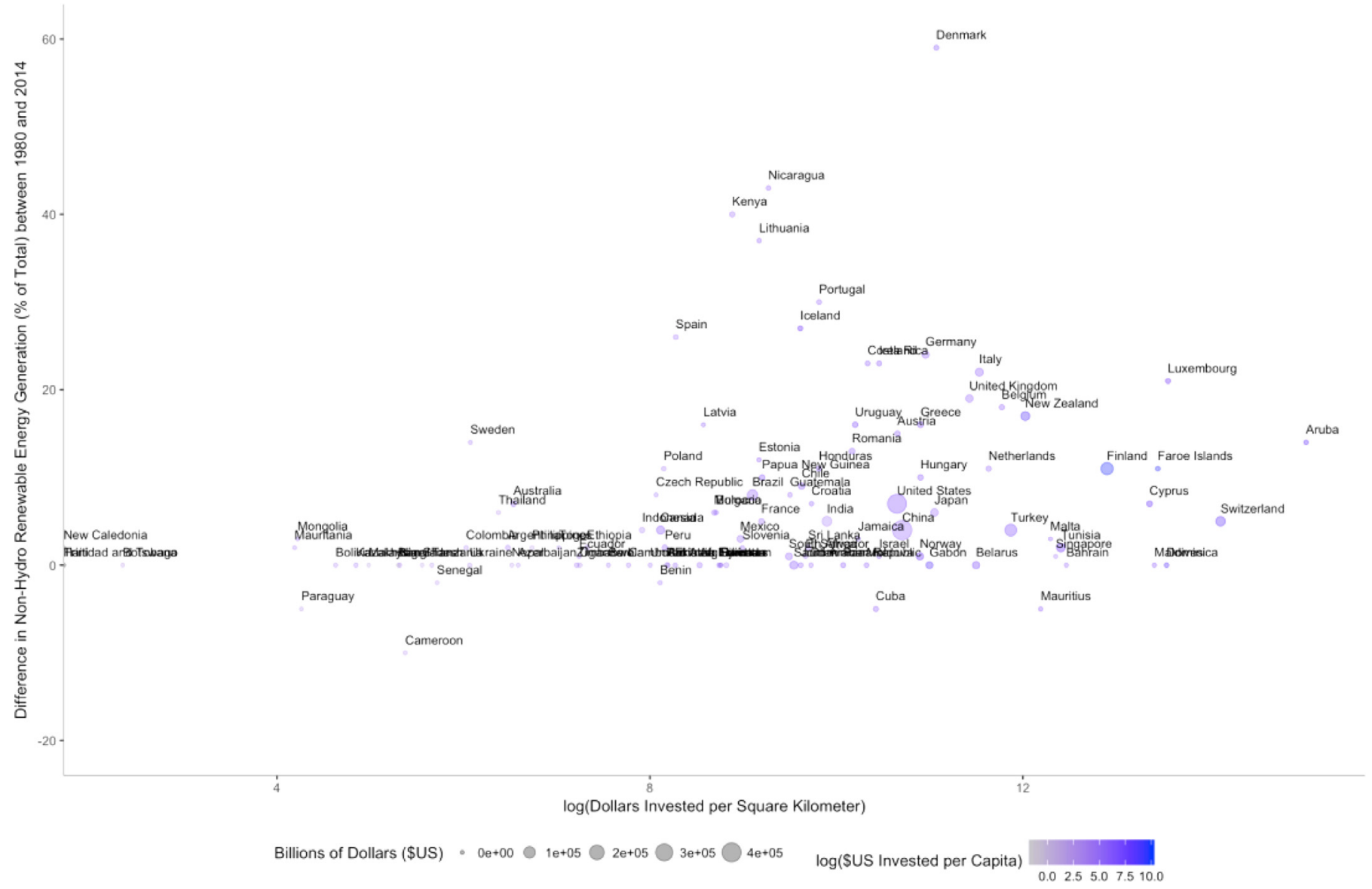

Fig. 4. Investments in renewable energy and decarbonization progress: the figure depicts the difference between total percentage generation from non-hydropower renewable resources between 1980 and 2014 as a function of renewable energy investments per capita and per $\mathrm{km}^{2}$.

sector transitions.

In recent years, behavioral research has brought to light the importance of understanding the diverse motivations that exist behind climate and environment-related goals, and the risks of using extrinsic motivators to facilitate long-term behavioral change. While this research has focused on the individual level, it has come to a broad consensus that a multitude of factors determine the adoption or aversion to adopting renewable energy technologies. These factors include appeal comparisons of monetary vs. non-monetary incentives (e.g., morals, environmental and climate change co-benefits) [96,97], the benefits and caveats of using competitions to achieving goals [98], and the perils of framing solutions around unique political ideologies [99]. For example, research in the United States has shown that, in some states, framing adoption of energy efficiency technology as an environmental beneficial solution can be detrimental to its adoption [99]. A desire to understand the motivations through which individuals may adopt or fail to adopt a behavior change or a new technology ties many of these studies together, generally finding that intrinsic motivation can be one of the most effective mechanisms for inducing long-term behavioral change [97,100-103].

Frameworks for designing support mechanisms for electricity sector level decarbonization could borrow intellectually from self-determination and intrinsic motivation theory in behavioral research $[104,105]$. Generally, the theory suggests that motivation appears across a continuum of extrinsic and intrinsic processes, in which pure intrinsic motivation is guided by interest, enjoyment, and inherent satisfaction, and pure extrinsic motivation is guided by group compliance, and the presence of external rewards and punishments [104,105]. The theory suggests that extrinsic motivators (e.g., monetary rewards and punishments) may often forestall intrinsic motivation and merely provide short-term change simply as compliance, and efforts to change may quickly end if the incentive or reward is removed. Considering global decarbonization frameworks, we argue that it is crucial to think about a country's historical motivations when enacting change in order to design adequate support mechanisms. Local and global environmental challenges, climate mitigation, technological innovation and leadership, energy independence and national security, the creation of niche markets and new industries, economic efficiency, group compliance, and need for foreign direct investment are a few of the motivators that may drive electricity sector level decarbonization.

Results from our analysis and literature review suggest the hypothesis that framing decarbonization under an over-arching motivation of climate change mitigation might be disadvantageous for longterm progress. Instead, support mechanisms could be designed by first understanding the unique motivations of countries, and by working with local change agents to design strategies that best fit their inherent characteristics and enabling environments. We do not aim to oversimply the decision-making process around low-carbon transitions by bringing in elements of behavioral research into the discussion; or represent the decision-making process as if it were coming from a unified decision-making body. Instead, our analysis aims to enrichen the discussion by bringing new elements that are not often discussed in the transitions literature. Indeed, as we have previously shown, the data, literature, and historical evidence suggest that countries chose different electricity generation technologies over others through a complicated process of opportunistic investments, cost competitiveness, natural resource endowments, policies, and individual motivators, among others.

To provide an example for framing this hypothesis, we construct a decarbonization motivation spectrum using data from the Social Progress Imperative, the Quality of Governance Initiative, the Yale 

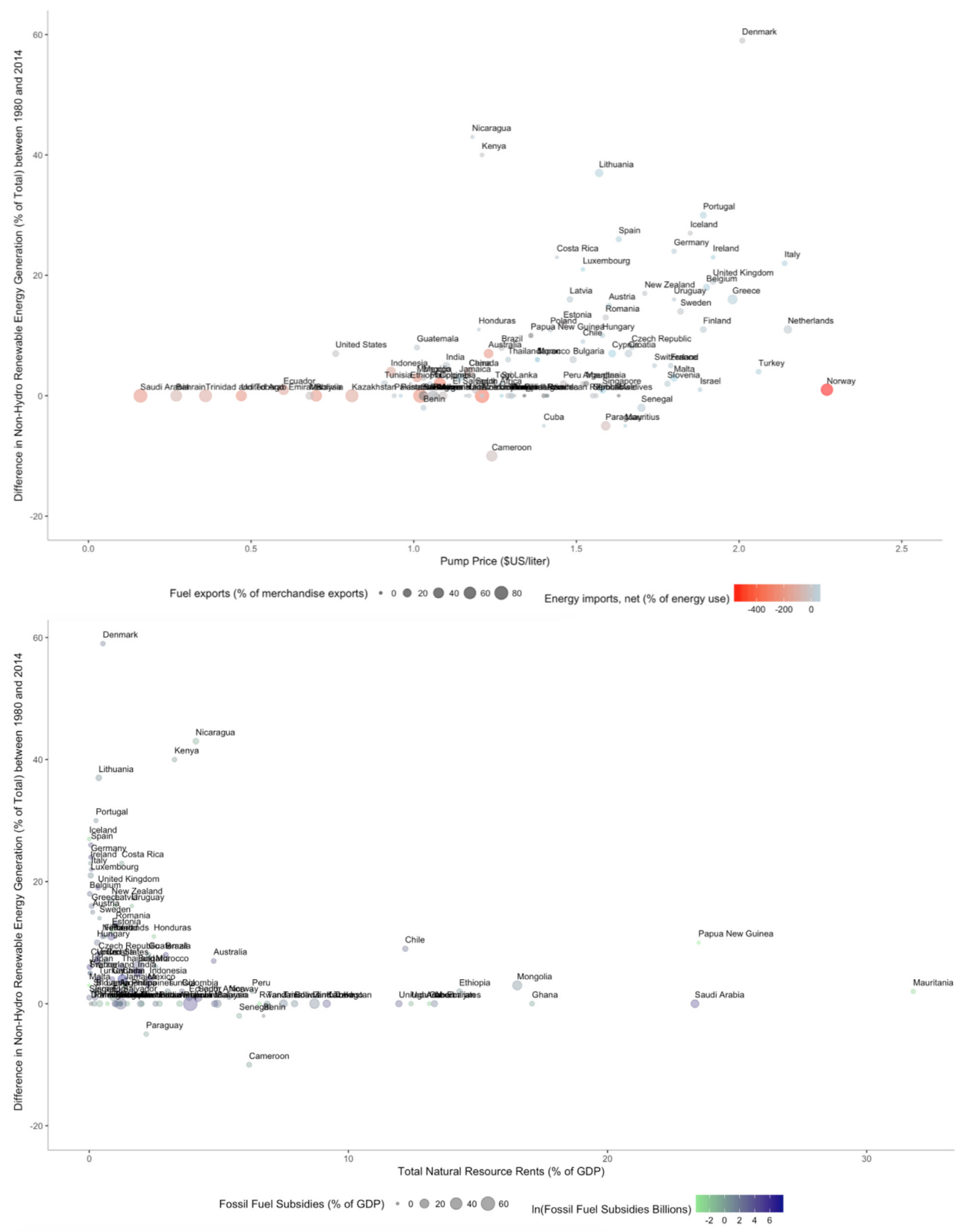

Fig. 5. Energy prices, fossil fuel subsidies, mineral and fossil fuel resource dependency and decarbonization progress: the figure depicts the difference between total percentage generation from non-hydropower renewable resources between 1980 and 2014 as a function of energy prices, dependency on resource rents and fossil fuel subsidies.

Environmental Performance Index, the Global Footprint Network and the World Bank Development Indicators $[63,66,60,58,65]$ to create proxies for three key motivators: social progress, local sustainability, and desire for energy independence. We scale these metrics and assign a score to each country across the sum of these three motivators, and plot the score against a dependent variable tracking decarbonization progress. We find a change in the slope at a motivational score of 1.75 (observed as an elbow in Fig. 6), with countries that score higher along 


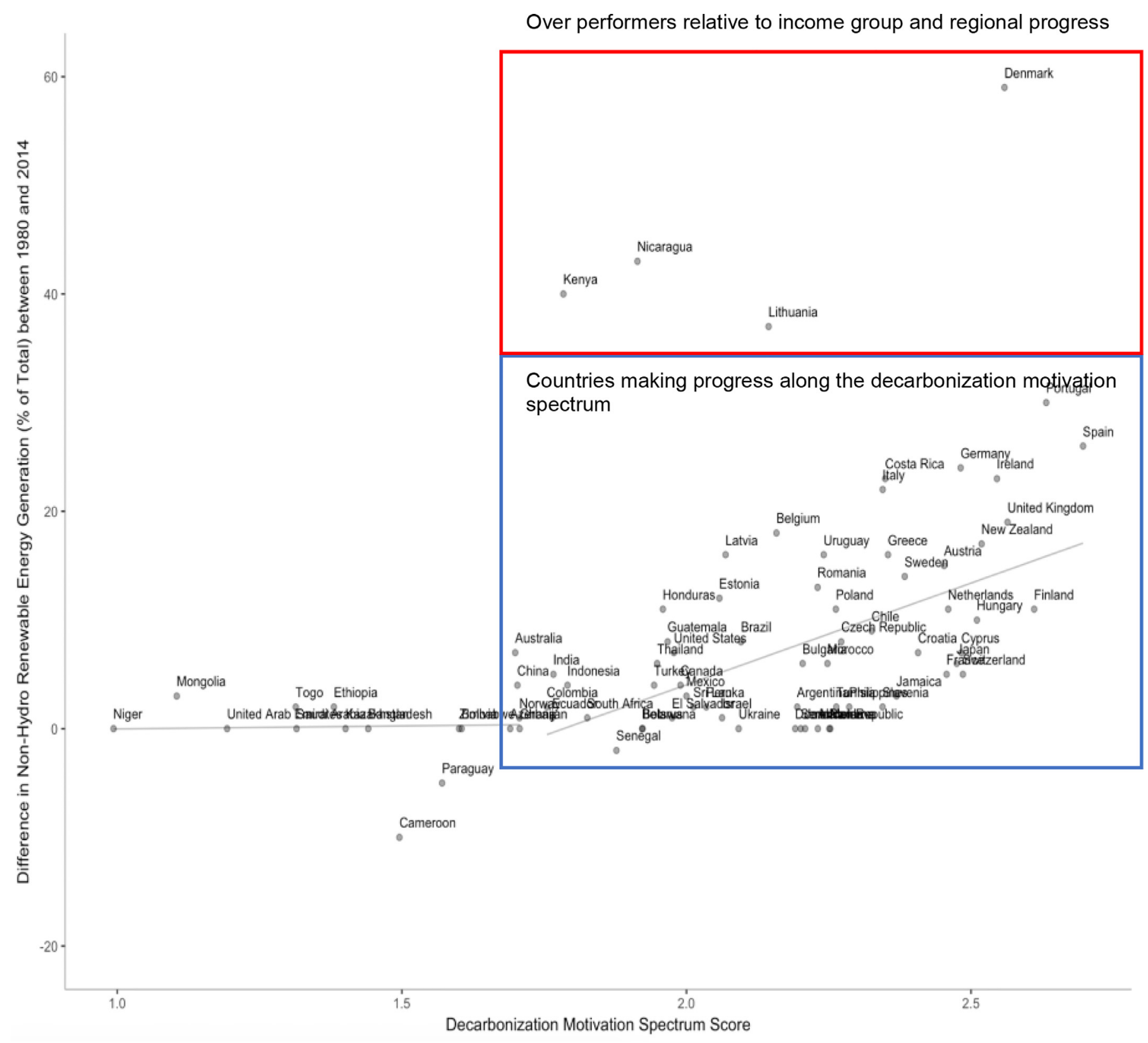

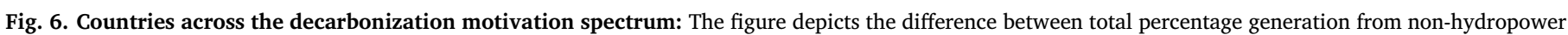

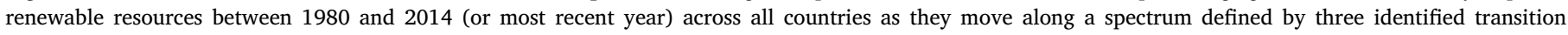
motivators: local sustainability, social progress, and energy independence. A change in the slope appears at a threshold score of 1.75 .

the motivational spectrum having made greater progress towards decarbonization. There are four outliers: Kenya, Nicaragua, Denmark and Lithuania - all over-performers relative to their income groups - and with different motivations for sustained decarbonization progress.

To help construct questions around this hypothesis, we provide a conceptual framework for a country's decarbonization pathway (Fig. 7). First, we hypothesize that one must understand the unique intrinsic motivations that could drive change in different countries, and then, the inherent characteristics (unchangeable, or very hard to change) and enabling environments (constantly evolving) are taken into account to design and implement support mechanisms to promote decarbonization (see Supplementary Information for details).

\section{Conclusion}

This research suggests that there is not one major driver of decarbonization, but rather, a multitude of factors that can contribute to transformative progress. It also presents the hypothesis that clustering the factors that foster decarbonization into binary categories of 'policy and non-policy drivers' is too limiting, and thus proposes three alternative categories - inherent characteristics, enabling environments and motivations. Our literature review and analysis suggest that globally, there are many countries with favorable combinations of inherent characteristics and enabling environments for kindling decarbonization that remain, however, in the path towards carbon lock-in. This, we argue, can be prevented and we suggest four hypotheses worth investigating to reinvigorate global decarbonization progress, as follows:

\subsection{Identify and invest in pockets of demand-side opportunity}

Our analysis suggests that there are favorable enabling environments and inherent characteristics that enable decarbonization to occur 


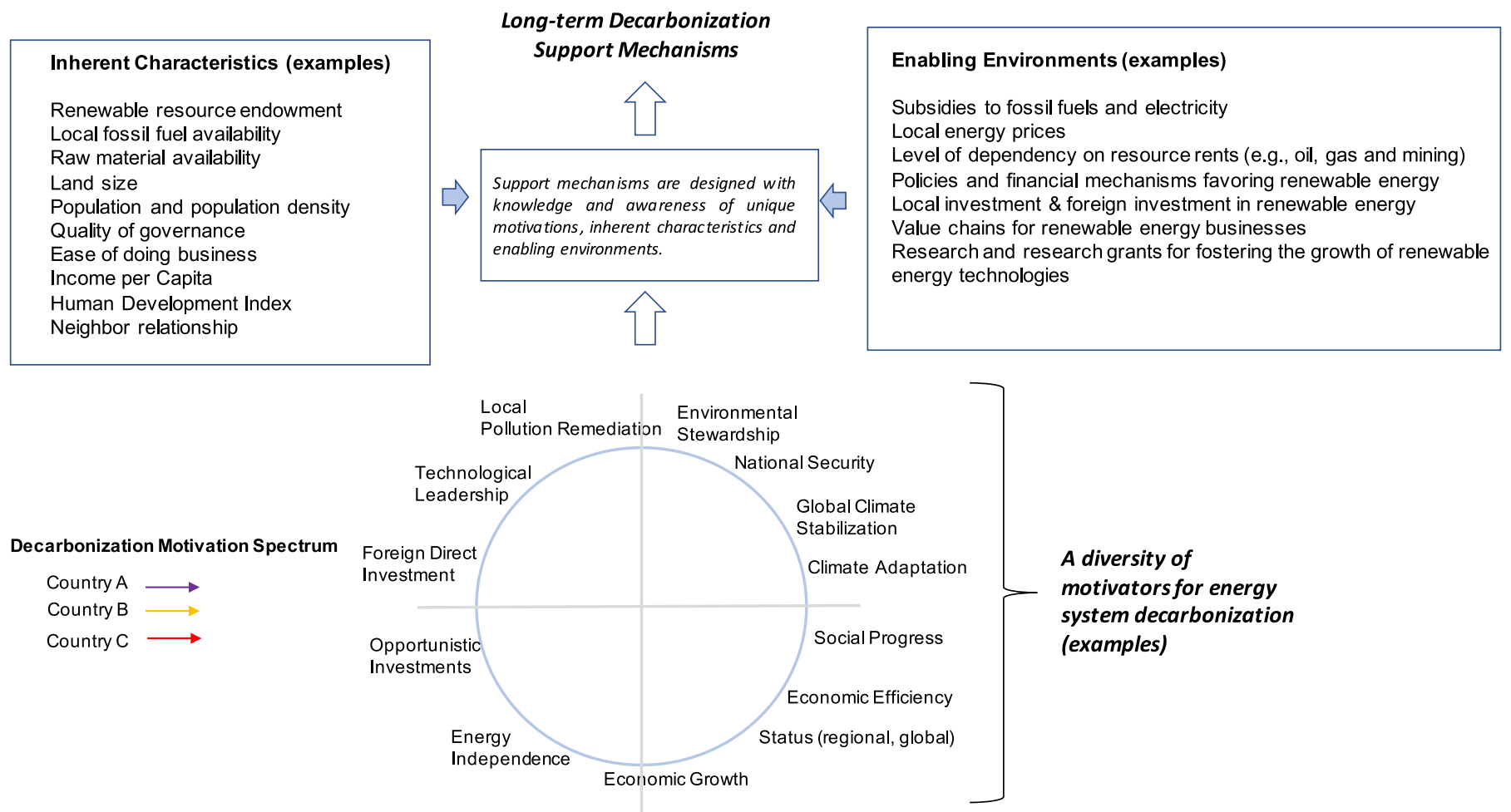

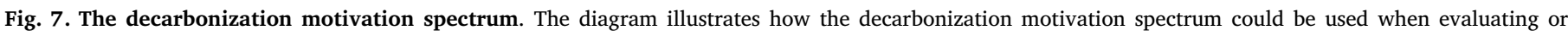

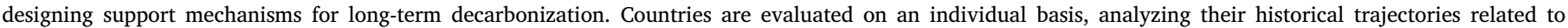

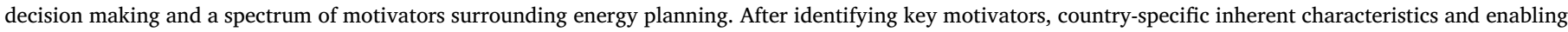
environments are considered in the design of long-term decarbonization support mechanisms.

rapidly, and unfavorable conditions that slow down decarbonization progress. Identifying and tapping into pockets of opportunity with favorable conditions in order to support neighbor and technology diffusion effects across a diversity of regions, incomes, and levels of development could be a way to spark progress. To do this, support mechanisms could be tailored uniquely to fit the inherent characteristics, enabling environments and motivations of a particular country. While most energy system decarbonization analyses focus on supplyside opportunities (e.g., renewable resource potential maps), we argue that it may be equally or more important to focus on country-specific demand-side drivers (identified by characterizing the enabling environment, inherent characteristics and motivations) and create a diversity of mechanisms to support them.

\subsection{Diversify the types of support mechanisms for decarbonization}

While the 21st Conference of the Parties meeting in Paris was successful due to the number of parties that submitted Intended Nationally Determined Contributions (INDCs), as well as the types of proposals that were put forward, recent analysis of the INDCs also suggests that these goals would not be sufficient to meet current global stabilization targets $[106,64]$. More importantly, there is an absence of support mechanisms that could tie a country's immediate needs and its intrinsic motivations to the long-term decarbonization goals and strategies stated in its INDCs. For example, some countries might be motivated by political and technological leadership, while others might be more motivated by national security, energy access and economic efficiency. Designing diverse support mechanisms, such as pay by performance goals, financing country-specific intrinsic motivators, local capacity building, and technological partnerships, that are reflective of the diversity of motivations could support clusters of countries unified by similar motivations. These clusters could encourage countries to learn from each other and try new ways of thinking about energy transitions, while working on their country-specific goals that in turn support progress towards decarbonization.

\subsection{Diversify the change agents that receive support for decarbonization}

In some countries, government institutions can foster top-down enabling environments for decarbonization. However, in other countries, government institutions can create roadblocks to energy system transformation [51,52]. As the energy transitions literature suggests, the repertoire of policies and institution types designed to support late technology adopters should be very different from those for first adopters and early pioneers, especially if the technology carries low risk $[50,27]$. Recognizing the appropriate change agents is key to designing support mechanisms that work specifically for countries who want to simply adopt technology, and do not seek to build research and development capacity like first adopters tend to prefer. To tap these pockets of opportunity, it is crucial to identify local successful change agents and provide support mechanisms that help them achieve their goals.

\subsection{Think beyond energy and support non-optimal pathways}

While it is useful to develop and analyze optimal techno-economic decarbonization pathways, in reality, most countries have complex political, socio-economic and cultural constraints that are not accounted for in such analyses, making engineered optimal pathways unattainable. A narrow focus on techno-economic optimality could be detrimental to realizing even modest progress on decarbonization. For example, countries where local pollution, water scarcity and management, garbage, or deforestation pathways might be immediate pressing issues, a narrow focus on least-cost technologically optimal energy pathways could overplay the promise of large-scale wind and solar developments, as compared to alternative solutions including methane 
collecting at landfills, water use efficiency programs (that in turn save energy), or funding for inclusive and fair conservation land management practices that may in fact be better suited for a particular country.

There are many countries around the world with favorable inherent characteristics and enabling environments features for long-term decarbonization, but also many without them. Our analysis presents the hypothesis that it is crucial for change agents, policymakers, and financiers to understand the roles of intrinsic motivation, inherent characteristics and enabling environments in finding new pockets of investment for renewable energy. This is corroborated by recent literature $[96,97,99-102]$ that suggest a wide spectrum of features that foster decarbonization ranging from sustainability, to energy independence and national security, to technological leadership and social progress [107]. Designing support mechanisms that are encompassing of this wide spectrum of motivations is crucial for sparking decarbonization across incomes, regions, and levels of human development

We conclude by highlighting several limitations in our approach. Throughout the manuscript, we mention the political economy and the historical development of renewable resources in different regions and countries. However, we have not included variables that can accurately capture these important components. Variables that could be included in future analysis are a breakdown of all policy types by implementation year and by country, variables that capture the forms of government in a country and how they have been changing over time, and the political support that these policies have, among other variables. In addition, future research could more carefully select variables included in the analysis. This includes variables that might be missing (e.g., political economy variables) and removing variables that might be highly correlated with each other. There are also gaps and limitations in our methodology. While PCA and PCR are useful for dealing with highly correlated variables, there is merit in removing variables that are highly correlated as this may cause the PCA to overemphasize the contribution of nearly-redundant variables. Setting a rigorous methodology to continuously collect data from all the sources in this analysis, and continuously improving the prediction of decarbonization progress for different groupings and clusters across enabling environments, motivations, and inherent characteristics would be an incredibly beneficial and useful space for future research to support the design of more successful mechanisms and accelerate the pace of low-carbon electricity sector transitions around the world.

\section{Data for reference}

All code and data in this analysis is available upon request.

\section{Declaration of Competing Interest}

The authors declare no conflict of interest.

\section{Supplementary materials}

Supplementary material associated with this article can be found, in the online version, at doi:10.1016/j.erss.2019.101343.

\section{References}

[1] A.T.C.J. Dangerman, H.J. Schellnhuber, Energy systems transformation, Proc. Natl. Acad. Sci. 110 (7) (2013) E549-E558, https://doi.org/10.1073/pnas. 1219791110

[2] P. Friedlingstein, C. Huntingford, More frequent moments in the climate change debate as emissions continue, Environ. Res. Lett. 10 (2015) 1-4.

[3] G.C.I. McJeon, J.A. E., A.A. F., N.E. H., J. A., G.R. A, K.V. C, L.E. C, J. C., M. J. P. K, J. M., A. M., P. P., The contribution of Paris to limit global warming to $2^{\circ} \mathrm{C}$, Environ. Res. Lett. 10 (12) (2015) 125002, , https://doi.org/10.1088/1748-9326/ $10 / 12 / 125002$

[4] J.C.J.M. van den Bergh, Policies to enhance economic feasibility of a sustainable energy transition, Proc. Natl. Acad. Sci. 110 (7) (2013) 2436-2437, https://doi org/10.1073/pnas.1221894110.

[5] Bloomberg New Energy Finance. (2016). Climatescope 2016. Retrieved fromhttps://about.bnef.com/clean-energy-investment/.

[6] FS-UNEP. (2016). Global Trends in Renewable Energy. Retrieved fromhttp://fsunep-centre.org/sites/default/files/publications/ globaltrendsinrenewableenergyinvestment2016lowres_0.pdf.

[7] Kristin Seyboth, F. Sverrisson, F. Appavou, A. Brown, B. Epp, A. Leidreiter, ... B. Sovacool, Renewables 2016 Global Status Report. Global Status Report. (2016) ISBN978-3-9818107-0-7.

[8] A. Grubler, Time for a change: on the patterns of diffusion of innovation, Am. Acad. Arts. Sci. 125 (3) (1997) 14-32.

[9] N. Kilincata, Energy for sustainable development the evaluation of renewable energy policies across EU countries and us states: an econometric approach, Energy Sustain. Develop. 31 (2016) 83-90, https://doi.org/10.1016/j.esd.2015. 12.006.

[10] C. Wilson, A. Grübler, Lessons from the history of technological change for clean energy scenarios and policies, Nat. Resour. Forum. 35 (3) (2011) 165-184, https://doi.org/10.1111/j.1477-8947.2011.01386.x.

[11] Christopher Blackburn, Anthony Harding, J. Moreno-Cruz, Toward deep-decarbonization: an energy-service system framework, Curr. Sustain. Renew. Energy Rep. 4 (4) (2017) 181-190.

[12] S. Carley, State renewable energy electricity policies : an empirical evaluation of effectiveness, Energy Policy 37 (8) (2009) 3071-3081, https://doi.org/10.1016/j. enpol.2009.03.062.

[13] S. Carley, E. Baldwin, L.M. Maclean, J.N. Brass, Global expansion of renewable energy generation: an analysis of policy instruments, Environ. Resour. Econ. 68 (2) (2017) 397-440, https://doi.org/10.1007/s10640-016-0025-3.

[14] A. Cherp, V. Vinichenko, J. Jewell, E. Brutschin, B. Sovacool, Integrating technoeconomic, socio-technical and political perspectives on national energy transitions: a meta-theoretical framework, Energy Res. Soc. Sci. 37 (January 2017) (2018) 175-190, https://doi.org/10.1016/j.erss.2017.09.015.

[15] Menz, F.C., \& Vachon, S. (2006). The effectiveness of different policy regimes for promoting wind power: experiences from the states, 34, 1786-1796. 10.1016/j. enpol.2004.12.018.

[16] G. Shrimali, J. Kniefel, Are government policies effective in promoting deployment of renewable electricity resources, Energy Policy 39 (9) (2011) 4726-4741, https://doi.org/10.1016/j.enpol.2011.06.055.

[17] H. Yin, N. Powers, Do state renewable portfolio standards promote in-state renewable generation <, Energy Policy 38 (2) (2010) 1140-1149, https://doi.org/ 10.1016/j.enpol.2009.10.067.

[18] B.F.W. Geels, K. Benjamin, T. Schwanen, S. Sorrell, Accelerating innovation is as important as climate policy, Science 357 (6357) (2017) 1242-1244.

[19] J. Rockström, O. Gaffney, J. Rogelj, M. Meinshausen, N. Nakicenovic, H.J. Schellnhuber, A roadmap for rapid decarbonization, Science 355 (6331) (2017) 1269-1271.

[20] B.K. Sovacool, How long will it take? conceptualizing the temporal dynamics of energy transitions, Energy Research and Social Science 13 (2016) 202-215, https://doi.org/10.1016/j.erss.2015.12.020.

[21] I. Cadoret, F. Padovano, The political drivers of renewable energies policies Energy Econ. 56 (2016) (2020) 261-269, https://doi.org/10.1016/j.eneco.2016. 03.003.

[22] Cheon, A., \& Urpelainen, J. (2013). How do competing interest groups influence environmental policy? The case of renewable electricity in industrialized democracies, 1989 - 2007. 10.1111/1467-9248.12006.

[23] G. Bridge, S. Bouzarovski, M. Bradshaw, N. Eyre, Geographies of energy transition : space, place and the low-carbon economy, Energy Policy 53 (2013) 331-340.

[24] J. Buen, Danish and norwegian wind industry: the relationship between policy instruments, innovation and diffusion, Energy Policy 34 (2006) 3887-3897, https://doi.org/10.1016/j.enpol.2005.09.003.

[25] C. Doblinger, B. Soppe, Change-actors in the US . electric energy system : the role of environmental groups in utility adoption and diffusion of wind power, Energy Policy 61 (2013) 274-284.

[26] J. Schot, L. Kanger, G. Verbong, The roles of users in shaping transitions to new energy systems, Nat. Energy 1 (5) (2016) 16054, https://doi.org/10.1038/ nenergy.2016.54.

[27] A. Grubler, Energy transitions research: insights and cautionary tales, Energy Policy 50 (2012) 8-16, https://doi.org/10.1016/j.enpol.2012.02.070.

[28] J.S. Lacerda, J.C.J.M. Van Den Bergh, International diffusion of renewable energy innovations: lessons from the lead markets for wind power in China, Germany and USA, Energies 7 (12) (2014) 8236-8263, https://doi.org/10.3390/en7128236.

[29] Y. Qiu, Three Essays on the Diffusion of Clean Energy Technologies, Stanford Univesity, 2012 Retrieved from https://stacks.stanford.edu/file/ druid:ft095rz4564/Qiu dissertation 2012 08-augmented.pdf.

[30] M. Albani, A. Bühner-blaschke, N. Denis, A. Granskog, Bioenergy in Europe: A New Beginning — Or the End of the Road? (2014) Retrieved from https://www. mckinsey.com/business-functions/sustainability-and-resource-productivity/ourinsights/bioenergy-in-europe-a-new-beginning-or-the-end.

[31] Didier Bourguignon, Biomass for Electricity and Heating Opportunities and Challenges, (2015) Retrieved from http://www.europarl.europa.eu/RegData/ etudes/BRIE/2015/568329/EPRS_BRI(2015)568329_EN.pdf.

[32] K. Rademaekers, Study on the Evolution of Some Deforestation Drivers and their Potential Impacts on the Costs of an Avoiding Deforestation Scheme, (2010) Retrieved from http://ec.europa.eu/environment/enveco/biodiversity/pdf/ deforestation_drivers_annexes.pdf.

[33] P. Ruiz, Biomass Green Energy Future, (2005) Retrieved from https://ec.europa. eu/energy/en/topics/renewable-energy/biomass. 
[34] U. Adhikari, A.P. Nejadhashemi, S.A. Woznicki, Climate change and eastern Africa : a review of impact on major crops, Food Energy Secur. 4 (2) (2015), https://doi.org/10.1002/fes3.61.

[35] T.V. Callaghan, P.J. Bacon, D.K. Lindley, A.I. Moghraby, The energy crisis in the Sudan : alternative supplies of biomass, Biomass 8 (1985) 217-232.

[36] IAE., Cuba a Country Profile on Sustainable Energy Development, (2008) Retrieved from http://www-pub.iaea.org/books/IAEABooks/7770/Cuba-ACountry-Profile-on-Sustainable-Energy-Development.

[37] G. Kabiri, Kenya: Poaching Sugarcane, (2012) Retrieved August 5, 2014, from https://www.ft.com/content/1fdffofe-5dc9-11e3-95bd-00144feabdc0.

[38] R. Loehr, Diffusion of Biomass Energy Technologies in Developing Countries (1984), first ed., National Academy Press, Washington, D.C., 1984.

[39] Organization of American States, Toward a National Energy Policy Assessment of the Energy Sector in Belize, (2011) Retrieved from https://hub.globalccsinstitute. com/publications/toward-national-energy-policy-assessment-energy-sectorbelize.

[40] M. Teklemariam, A. Ababa, Overview of Geothermal Resource Utilization and Potential in East African Rift System, (2007) Retrieved from http://www.grmfeastafrica.org/database/teklemariam2005 overview of geothermal resource utilization and potential in east african rift system.pdf.

[41] J. Armstrong, Best Practices for Geothermal Power Risk Reduction Workshop Follow - Up Manual, (2014) Retrieved from http://geo-energy.org/reports/ Geothermal Best Practices Publication Final CL188154847.pdf.

[42] ESMAP, Comparative Analysis of Approaches to Geothermal Resource Risk Mitigation, (2016)

[43] C. Davidson, D. Steinberg, R. Margolis, C. Davidson, E. Drury, A. Lopez, R. Elmore, Modeling photovoltaic diffusion: an analysis of geospatial datasets, Environ. Res. Lett. 9 (2014) 1-15, https://doi.org/10.1088/1748-9326/9/7/074009.

[44] Dechezlepr, A., Glachant, M., Union, E., Portf, R., Mechanism, C.D., Agency, I.E., \& Bank, W. (2009). The rapid growth of wind power is a model of successful public policy. Retrieved September 10, 2018, fromhttp://blogs.lse.ac.uk/ politicsandpolicy/archives/25014.

[45] M. Guidolin, C. Mortarino, Technological forecasting \& social change crosscountry diffusion of photovoltaic systems : modelling choices and forecasts for national adoption patterns, Technol. Forecast. Soc. Change 77 (2) (2010) 279-296, https://doi.org/10.1016/j.techfore.2009.07.003.

[46] G.E.R. Klaassen, P. So, Wind power in Europe : a simultaneous innovation - diffusion model, Environ. Resour. Econ. 36 (2007) 163-190, https://doi.org/10. 1007/s10640-006-9025-z.

[47] C. Lee, Influence of local environmental, social, economic and political variables on the spatial distribution of residential solar PV arrays across the United States, Energy Policy 47 (2012) 332-344.

[48] P.J. Burke, Income, resources, and electricity mix, Energy Econ. 32 (3) (2010) 616-626, https://doi.org/10.1016/j.eneco.2010.01.012.

[49] J. Gosens, F. Hedenus, B.A. Sandén, Faster market growth of wind and PV in late adopters due to global experience build-up, Energy 131 (2017) 267-278, https:// doi.org/10.1016/j.energy.2017.05.046.

[50] E. Baldwin, S. Carley, J.N. Brass, L.M. Maclean, E. Baldwin, S. Carley, ... L.M. Maclean, Global renewable electricity policy: a comparative policy analysis of countries by income status global renewable electricity policy: a comparative policy analysis of countries by income status, J. Compar. Policy Anal. 19 (3) (2017) 277-298, https://doi.org/10.1080/13876988.2016.1166866.

[51] A. Eberhard, K. Gratwick, E. Morello, P. Antmann, Accelerating investments in power in sub-Saharan Africa, Nat. Energy 2 (2) (2017) 17005, https://doi.org/10. 1038/nenergy. 2017.5.

[52] C.A. Friebe, P.Von Flotow, F.A. Täube, Exploring technology diffusion in emerging markets - the role of public policy for wind energy, Energy Policy 70 (2014) 217-226.

[53] M.A. Delmas, M.J. Montes-sancho, US state policies for renewable energy : context and effectiveness \$, Energy Policy 39 (5) (2011) 2273-2288, https://doi.org/10. 1016/j.enpol.2011.01.034.

[54] S. Jenner, F. Groba, J. Indvik, Assessing the strength and effectiveness of renewable electricity feed-in tariffs in European Union countries, Energy Policy 52 (2013) 385-401, https://doi.org/10.1016/j.enpol.2012.09.046.

[55] Jiawei Han, Micheline Kamber, J. Pei, Data Mining Concepts and Techniques, third, Elsevier, Waltham, MA, 2012 Retrieved from http://myweb.sabanciuniv. edu/rdehkharghani/files/2016/02/The-Morgan-Kaufmann-Series-in-DataManagement-Systems-Jiawei-Han-Micheline-Kamber-Jian-Pei-Data-Mining.Concepts-and-Techniques-3rd-Edition-Morgan-Kaufmann-2011.pdf.

[56] P.C. Stern, B.K. Sovacool, T. Dietz, Towards a science of climate and energy choices, Nat. Clim. Chang 6 (6) (2016) 547-555, https://doi.org/10.1038/ nclimate3027.

[57] G. Wong-Parodi, T. Krishnamurti, A. Davis, D. Schwartz, B. Fischhoff, A decision science approach for integrating social science in climate and energy solutions, Nat. Clim. Chang 6 (6) (2016) 563-569, https://doi.org/10.1038/nclimate2917.

[58] WB., World Bank Development Indicators, (2016) Retrieved August 15, 2014 from https://data.worldbank.org/data-catalog/world-development-indicators.

[59] EIA, Energy Information Administration International Data, (2016) Retrieved August 15, 2014, from http://www.eia.gov/beta/international/.

[60] University of Gothemberg, Quality of Governance Initiative, (2016) Retrieved August 15, 2014, from http://qog.pol.gu.se/.

[61] IEA/IRENA, IEA/IRENA Joint Policies and Measures Database, (2016) Retrieved August 15, 2016, from https://www.iea.org/policiesandmeasures/.

[62] IMF, International Monetary Fund Fossil Fuel Subsidies Database, (2016) Retrieved February 10, 2018, from https://www.imf.org/en/News/Articles/ 2015/09/28/04/53/sonew070215a.
[63] Global Footprint Network, Global Footprint Network, (2016) Retrieved August 15, 2014, from https://www.footprintnetwork.org/.

[64] United Nations, United Nations Human Development Indicators, (2016) Retrieved August 15, 2014, from http://hdr.undp.org/en/content/human-development index-hdi.

[65] Yale., Yale Environmental Performance Index, (2016) Retrieved August 15, 2014, from http://epi.yale.edu/.

[66] SPI., The Social Progress Imperative, (2016) Retrieved August 15, 2014, from http://www.socialprogressimperative.org/.

[67] World Energy Council, World Energy Council, (2016) Retrieved August 15, 2014 from https://www.worldenergy.org/.

[68] J. Jackson, A User's Guide to Principal Components, John Wiley \& Sons, New York, 1991.

[69] I.T. Jolliffe, A note on the use of principal components in regression, J. R. Stat. Soc. (1982).

[70] John Mount, N. Zumei, Y-Aware principal component regression, (2017) Retrieved September 10, 2018, from https://github.com/WinVector/Examples/tree/master/ PCR.

[71] D. Ponce de Leon Barido, J. Johnston, M. Moncada, D. Callaway, D. Kammen, Evidence and future scenarios of a low-carbon energy transition in Central America : a case study in Nicaragua, Environ. Res. Lett. 10 (2015) 1-11.

[72] K. Nuthall, Trading Power between Europe and North Africa, (2016) Retrieved August 15, 2014, from http://www.powerengineeringint.com/articles/print/ volume-21/issue-5/features/trading-power-between-europe-and-north-africa. html.

[73] C. Werber, Quartz - Tired of Importing Almost All Its Energy, Morocco Has Built Africa's Biggest Solar Farm, (2016) Retrieved August 15, 2014, from https://qz. com/533187/tired-of-importing-almost-all-its-energy-morocco-has-built-africasbiggest-solar-farm/.

[74] A. Critchley, Honduras emerges as Central America's Solar Success Story, (2015) Retrieved February 10, 2018, from https://www.greentechmedia.com/articles/ $\mathrm{read} /$ honduras-emerges-as-central-americas-solar-success-story.

[75] López, B.D. (n.d.). Honduras is the first nation with $10 \%$ solar in its electricity mix Retrieved August 15, 2014, fromhttps://www.pv-magazine.com/2017/01/30/ honduras-first-country-in-the-world-with-10-of-solar-in-its-electricity-mix/.

[76] A. Eberhard, K. Gratwick, The Kenyan IPP experience, J. Energy. South Afri 16 (4) (2005) 152-165.

[77] T. Kenning, Brazil Approves "Historic" Net Metering Revision, (2016) Retrieved August 15, 2014, from https://www.pv-tech.org/news/brazil-approves-historic net-metering-revision.

[78] G. Meyers, Net Metering Boost Takes Place in Brazil, (2016) Retrieved August 15 2014, from https://cleantechnica.com/2015/11/30/net-metering-boost-takesplace-brazil/.

[79] P. Fairley, Chile's Hybrid PV-Solar Thermal Power Stations, (2015) Retrieved August 15, 2014, from https://www.ecnmag.com/news/2015/11/chiles-hybridpv-solar-thermal-power-stations.

[80] M. Bolinger, Community wind power ownership schemes in Europe and their relevance to the United States, Power 73 (May) (2001) Retrieved from http://eetd. lbl.gov/EA/EMP/.

[81] IRENA, \& GWEC., 30 Years of Policies for Wind Energy, (2011), pp. 54-63.

[82] D. Mcglone, What can we learn from Denmark's landmark wind generation? Planet Forward (2015) Retrieved from http://www.planetforward.org/idea/what-canwe-learn-from-denmarks-landmark-wind-generation.

[83] C. Silva, Factors Influencing the Development of Local Renewable Energy Strategies: The Cases of Lolland and Samso Islands in Denmark, Lund University, 2008 Retrieved from https://www.lumes.lu.se/sites/lumes.lu.se/files/eduardo torres.pdf.

[84] F. Tranaes, Danish Wind Energy, (1996) Retrieved from www.dkvind.dk.

[85] TSV., Poul La Cour: The Social Vision, (1997) Retrieved February 10, 2018, from http://www.poullacour.dk/engelsk/vision.htm.

[86] California Air Resources Board, Retrieved February 2, 2018, from, California's 2030 Climate Commitment, (2016) https://www.arb.ca.gov/html/fact sheets/ 2030_renewables.pdf.

[87] HCEI, Hawaii Clean Energy Initiative, (2017) Retrieved February 10, 2018, from http://www.hawaiicleanenergyinitiative.org/.

[88] K. Kennedy, New York Adopts Historic "50 by "30" Renewables Goal | NRDC.", (2016) Retrieved February 10, 2018, from https://www.nrdc.org/experts/kitkennedy/new-york-adopts-historic-50-30-renewables-goal.

[89] Z. Shahan, Top Solar Power States Per Capita (Updated) vs Top Solar Policy Leaders (CleanTechnica Exclusive), (2013) Retrieved February 10, 2018, from https://cleantechnica.com/2013/06/25/solar-power-by-state-solar-rankings-bystate/.

[90] EIA Staff, EIA's AEO2017 Projects the United States to be a Net Energy Exporter in Most Cases, (2017) Retrieved February 10, 2018, from http://www.eia.gov/ todayinenergy/detail.php?id $=29433$.

[91] K.C. Seto, S.J. Davis, R.B. Mitchell, E.C. Stokes, G. Unruh, D. Ürge-Vorsatz, Carbon lock-in: types, causes, and policy implications, Annu. Rev. Environ. Resour. 41 (1) (2016) 425-452, https://doi.org/10.1146/annurev-environ-110615-085934.

[92] J.C. Steckel, O. Edenhofer, M. Jakob, Drivers for the renaissance of coal, Proc Natl. Acad. Sci. 112 (29) (2015) E3775-E3781, https://doi.org/10.1073/pnas. 1422722112.

[93] OBG, Expanding the role of renewable energy in Papua New Gguinea, Oxford Business Group, 2016 Retrieved from https://www.oxfordbusinessgroup.com/ analysis/expanding-role-renewable-energy-png.

[94] E. Northrop, Papua New Guinea First to Finalize Climate Plan Under Paris Agreement, (2016) Retrieved from http://www.wri.org/blog/2016/03/papua- 
new-guinea-first-country-finalize-national-climate-plan-under-paris-agreement.

[95] WB., Papua New Guinea Overview, (2016) Retrieved February 10, 2018, from http://www.worldbank.org/en/country/png/overview.

[96] O.I. Asensio, M.A. Delmas, Nonprice incentives and energy conservation, Proc. Natl. Acad. Sci. 112 (6) (2015) E510-E515, https://doi.org/10.1073/pnas. 1401880112.

[97] J.W. Bolderdijk, L. Steg, E.S. Geller, P.K. Lehman, T. Postmes, Comparing the effectiveness of monetary versus moral motives in environmental campaigning, Nat. Clim. Chang 3 (4) (2012) 413-416, https://doi.org/10.1038/nclimate1767.

[98] H. Allcott, S. Mullainathan, Behavior and energy policy, Science 327 (5970) (2010) 1204-1205, https://doi.org/10.1126/science.1180775.

[99] D.M. Gromet, H. Kunreuther, R.P. Larrick, Political ideology affects energy-efficiency attitudes and choices, Proc. Natl. Acad. Sci. 110 (23) (2013) 9314-9319, https://doi.org/10.1073/pnas.1218453110.

[100] E.M. Markowitz, A.F. Shariff, Climate change and moral judgement, Nat. Clim. Chang 2 (4) (2012) 243-247, https://doi.org/10.1038/nclimate1378.

[101] I. Shalev, The climate change problem: promoting motivation for change when the map is not the territory, Front. Psychol. 6 (FEB) (2015) 1-4, https://doi.org/10. 3389/fpsyg.2015.00131.

[102] S. van der Linden, Intrinsic motivation and pro-environmental behaviour, Nat. Clim. Chang 5 (7) (2015) 612-613, https://doi.org/10.1038/nclimate2669.

[103] S. van der Linden, E. Maibach, A. Leiserowitz, Improving public engagement with climate change, Perspect. Psychol. Sci. 10 (6) (2015) 758-763, https://doi.org/10. $1177 / 1745691615598516$.

[104] E.L. Deci, R.M. Ryan, The "what" and "why" of goal pursuits: of behavior human needs and the self-determination, Psychol. Inq. 11 (4) (2000) 227-268, https:// doi.org/10.1207/S15327965PLI1104.

[105] R.M. Ryan, E.L. Deci, Self-determination theory and the facilitation of intrinsic motivation, Am. Psychol. 55 (1) (2000) 68-78, https://doi.org/10.1037/0003066X.55.1.68.

[106] J. Rogelj, M.Den Elzen, T. Fransen, H. Fekete, H. Winkler, R. Schaeffer, ... M. Meinshausen, Perspective: paris agreement climate proposals need boost to keep warming well below $2^{\circ} \mathrm{C}$, Nat. Clim. Chang 534 (June) (2016) 631-639, https://doi.org/10.1038/nature18307.

[107] J. Mochizuki, S.E. Chang, Disasters as opportunity for change: tsunami recovery and energy transition in Japan, Int. J. Disaster Risk Reduct. 21 (June 2016) (2017) 331-339, https://doi.org/10.1016/j.ijdrr.2017.01.009.

[108] C. Le Quéré, J.I. Korsbakken, C. Wilson, J. Tosun, R. Andrew, R.J. Andres, J.G. Canadell, A. Jordan, G.P. Peters, D.P. Van Vuuren, C. Le Quéré, J.I. Korsbakken, C. Wilson, J. Tosun, R. Andrew, R.J. Andres, J.G. Canadell, A. Jordan, G.P. Peters, D.P. V. V., Drivers of declining CO2 emissions in 18 developed economies, Nat. Clim. Chang. 9 (2019) 213-218 10.1038/s41558-019 0419-7.

[109] M. Aguirre, G. Ibikunle, Determinants of renewable energy growth : a global sample analysis, Energy Policy 69 (2014) 374-384, https://doi.org/10.1016/j. enpol.2014.02.036.

[110] E. Lachapelle, M. Paterson, Drivers of national climate policy, Climate Policy 13 (5) (2013), https://doi.org/10.1080/14693062.2013.811333.

[111] A. Masini, E. Menichetti, Technological forecasting \& social change investment decisions in the renewable energy sector: an analysis of non- fi nancial drivers, Technol. Forecast. Soc. Change 80 (3) (2013) 510-524, https://doi.org/10.1016/j. techfore.2012.08.003.

[112] Y. Zhao, K. Ki, L. Wang, Do renewable electricity policies promote renewable electricity generation? Evidence from panel data, Energy Policy 62 (2013) 887-897, https://doi.org/10.1016/j.enpol.2013.07.072

[113] A.C. Marques, J.A. Fuinhas, Are public policies towards renewables successful ? Evidence from European countries, Renew Energy 44 (2012) 109-118, https:// doi.org/10.1016/j.renene.2012.01.007.

[114] J. Gan, C.T. Smith, Drivers for renewable energy : a comparison among OECD countries, Biomass Bioenergy 35 (11) (2011) 4497-4503, https://doi.org/10. 1016/j.biombioe.2011.03.022.

[115] C. Marques, A. Fuinhas, J.R.P. Manso, Motivations driving renewable energy in European countries: a panel data approach, Energy Policy 38 (2010) 6877-6885, https://doi.org/10.1016/j.enpol.2010.07.003. 